\title{
Conceções de Estudantes Portugueses em Formação Inicial de Professores sobre a Evolução e a Origem da Vida
}

\section{Conceptions of Portuguese Preservice Teachers about Evolution and the Origin of Life}

\author{
Bento Cavadas ${ }^{\circledR}$ Portugal \\ Xana Sá-Pinto ${ }^{\circledR}$ Portugal
}

Este trabalho apresenta as conceções de estudantes portugueses em formação inicial de professores sobre a evolução, a origem da vida e o ensino da evolução. Para tal, foi aplicado a 41 estudantes um inquérito adaptado a partir do questionário BIOHEAD-CITIZEN. Os resultados mostram que os estudantes possuem crenças religiosas diversificadas, sendo a maior parte deístas. Apresentam principalmente conceções evolucionistas, sendo raras as conceções criacionistas dogmáticas. As conceções evolucionistas são superiores à proporção encontrada em participantes de outros estudos e, tal outros trabalhos evidenciam, coabitam com diversas crenças religiosas. Contudo, as reflexões dos estudantes em formação inicial de professores sobre a perspetiva da origem das espécies que defendem, mostram falhas na compreensão dos mecanismos da evolução. Apesar das conceções evolucionistas serem dominantes, a maioria dos estudantes considera também que os professores devem ensinar a evolução e o criacionismo ao mesmo tempo, de modo a deixar os alunos decidir sobre a posição que advogam sobre a origem das espécies. Dada a importância da evolução para a compreensão da natureza da ciência e os processos em biologia, este trabalho evidencia a necessidade do reforço da formação sobre evolução dos futuros professores.

Palavras-chave: Evolução; Formação inicial de professores; Origem da vida.

This work presents the conceptions of Portuguese preservice teachers (PSTs) about evolution, the origin of life and evolution teaching. With this aim, a survey adapted from the questionnaire BIOHEAD-CITIZEN was applied to 41 PSTs. Results show that PSTs have diversified religious beliefs, though most of them are deist. PSTs present mainly evolutionist conceptions and a few rare creationists beliefs. Rates of evolutionist conceptions are higher than those identified in similar surveys and coexist with diverse religious beliefs. However, PSTs' reflections about the origin of life reveal misconceptions about evolutionary processes. Although evolutionist conceptions are dominant, most PSTs believe teachers should teach evolution and creationism, and let students decide which position they agree with. Given the importance of evolution for understanding the nature of science and processes on Biology, this work highlights the need to reinforce the education of future teachers on evolution.

Keywords: Evolution; Initial teacher training; Origin of life. 


\section{Introdução}

O projeto europeu BIOHEAD-CITIZEN (2008) visou estudar o multiculturalismo e compreender como é que a biologia, a saúde e a educação ambiental podiam promover uma cidadania mais ativa, em 19 países. Por cidadania ativa entende-se a capacidade de um indivíduo em se envolver em ações para a mudança social, solidariedade para com o outro, participando em debates, particularmente em áreas de controvérsia, e mobilizando competências conducentes à argumentação de pontos vista alternativos (Ross, 2007). Um dos aspetos abordado no projeto foram os conhecimentos da população sobre a evolução. A evolução biológica refere-se a mudanças nas características físicas ou de comportamento de uma espécie ao longo de várias gerações (NASIM, 2008). Passados mais de dez anos após a conclusão do projeto importa aferir novamente os resultados da aplicação desse inquérito sobre a evolução. Nesse sentido, este estudo visou dar resposta ao seguinte problema:

Quais são as conceções de estudantes em formação inicial de professores sobre a evolução, a origem da vida e o ensino da evolução?

Para dar resposta a esse problema, identificaram-se os seguintes objetivos:

- Estudar a relação entre as crenças religiosas e a defesa de perspetivas evolucionistas ou criacionistas quanto à origem das espécies;

- Identificar o posicionamento (evolucionista ou criacionista) face ao aparecimento da vida e da espécie humana;

- Comparar a valorização de determinados fatores sobre a evolução das espécies;

- Identificar o posicionamento face ao ensino da evolução.

Tendo em conta que os professores têm um papel relevante na promoção de uma cidadania ativa e responsável, inevitavelmente assente numa forte literacia científica, importa esclarecer quais são os seus conhecimentos sobre a teoria que sustenta o conhecimento e orienta a investigação em biologia, a evolução. Apenas professores esclarecidos sobre esse assunto poderão ajudar os estudantes a compreender as evidências, científicas, os mecanismos e as implicações da evolução, o que é fundamental para uma educação em ciências com qualidade (NASIM, 2008).

\section{Conceções sobre evolução nos professores}

Uma das dez principais ideias da educação em ciências, é, de acordo com Harlen (2015), o facto da diversidade dos organismos, atuais ou extintos, ser o resultado da evolução. No entanto, apesar desta ser uma das ideias mais significativas em ciências, os professores nem sempre a conhecem ou ensinam. A esse respeito, o estudo realizado por Araújo et al. (2009) determinou que a quantidade de professores criacionistas da $1 .{ }^{\mathrm{a}}$ à $4 .^{\mathrm{a}}$ séries do Ensino Fundamental e de estudantes do curso de Pedagogia é elevada e está relacionada com a sua crença numa entidade divina. Em Portugal, 15 a 30\% dos professores possuem conceções criacionistas e aqueles que não possuem formação em biologia apresentam conceções criacionistas significativamente mais elevadas (26\%) do 
que aqueles que possuem formação em biologia (17\%) (Clément et al., 2008).

Os resultados anteriores sugerem que a formação em biologia poderá contribuir para o reforço do conhecimento dos professores sobre evolução e para rejeitarem o criacionismo como uma hipótese explicativa da origem das espécies. De facto, a formação em biologia parece ser essencial para a consolidação de ideias evolucionistas. Num estudo realizado por Silva et al. (2014) e que envolveu estudantes em formação inicial de professores na área das Ciências Biológicas, constatou-se que iniciam a sua formação com fortes conceções criacionistas. Contudo, algumas dessas conceções tendem a ser substituídas por conceções evolucionistas ao longo da frequência do curso. Esse estudo revelou também formas variadas de relação entre conceções da origem da vida vinculadas pela religião e pela ciência, que se moviam entre a aceitação, acomodação ou rejeição. No entanto, mesmo com formação em biologia, a aplicação de conceitos-chave da evolução parece ser difícil para os professores. Um estudo realizado por Nehm et al. (2009) mostrou que não existiam diferenças significativas quanto ao uso desses conceitos entre professores de biologia e outros professores numa atividade que consistia em explicar um cenário sobre evolução. Esses resultados mostram que, tal como sugerido por Ziadie e Andrews (2018), ainda é necessário compreender melhor o pensamento dos estudantes para desenvolver estratégias de ensino e de avaliação adequadas do seu conhecimento sobre evolução. De facto, embora existam evidências de que a frequência de cursos de biologia conduz ao aumento da compreensão da evolução por parte dos professores (Nehm \& Schonfeld, 2007; Silva et al. 2014; Stover \& Mabry, 2007), o aumento dessa compreensão pode não ser suficiente para que abandonem ideias que contradizem a evolução (Nehm \& Schonfeld, 2007).

Foram realizados também diversos estudos que revelam conceções inadequadas dos futuros professores sobre evolução. Zuzovsky (1994) concluiu que 19 dos 27 professores inquiridos revelaram ideias lamarckistas nas respostas a um questionário sobre evolução. O uso de conceções semelhantes por professores em formação também foi identificado em estudos mais recentes. O estudo de revisão realizado por Sickel e Friedrichsen (2013) mostrou que muitos professores possuem conceções inadequadas relacionadas com a seleção natural, tempo geológico e natureza da ciência, semelhantes às dos alunos. Em estudos com estudantes do ensino superior a frequentarem aulas de biologia, também foi encontrada uma elevada frequência de explicações teleológicas ou lamarckistas (Stover \& Mabry, 2007). Levesque e Guillaume (2010) mostraram que alguns professores acreditam que os seres humanos evoluíram ao longo de milhões de anos a partir de formas de vida mais simples, mas Deus guiou este processo, incluindo a criação do ser humano. Sickel e Friedrichsen (2013) referem que os professores do ensino básico são mais relutantes em aceitar a evolução do que os professores do ensino secundário e que são essencialmente três os fatores que se correlacionam com a sua aceitação da evolução: as crenças religiosas, a compreensão da natureza da ciência e o contacto com investigação sobre biologia e evolução. Fatores como as crenças religiosas e as conceções prévias também foram identificados como limitadores da compreensão 
da evolução em estudos cujos participantes são estudantes do ensino superior, embora não em formação de professores, como o de Alters e Nelson (2002).

Acerca da presença da evolução no currículo, Sickel e Friedrichsen (2013) concluíram que uma parte substancial dos professores acredita que a evolução não é uma parte essencial do currículo ou que tanto a evolução como o criacionismo devem ser ensinados. Relativamente a esse assunto, Kose (2010) mostrou que, na Turquia, cerca de $84 \%$ dos professores em formação inicial que participaram no seu estudo considerava que a evolução e o criacionismo deviam estar incluídos no currículo. Quanto ao ensino da evolução, um estudo realizado por Abrie (2010) com professores em formação inicial na África do Sul, mostrou que as respostas dos participantes, a maioria com convicções religiosas, dividia-se entre os que defendiam que os estudantes deviam ter a opção de não frequentar as aulas relacionadas com o ensino da evolução (44\%) e aqueles que consideravam que o estudo da evolução devia ser obrigatório (42\%).

\section{Aspetos metodológicos}

\section{Design do estudo}

Tendo em conta a questão-problema e os objetivos deste trabalho, realizou-se um estudo predominantemente quantitativo, quanto ao modo de abordagem, e descritivo (Vilelas, 2017), por aplicação de um inquérito.

\section{Participantes}

Os participantes neste estudo foram 41 estudantes que estavam a frequentar o $3^{\circ}$ ano do curso de licenciatura em Educação Básica de uma instituição de ensino superior politécnico portuguesa, no ano letivo 2019/20. Em Portugal, o curso de ensino superior de Educação Básica é a primeira etapa da formação profissional para a docência (Decreto-Lei n. ${ }^{\circ}$ 79/2014). Após a conclusão desse curso, os estudantes, para adquirirem habilitação profissional para a docência na educação pré-escolar, no $10^{\circ}$ ciclo do ensino básico e em alguns grupos de recrutamento no $2 .^{\circ}$ ciclo do ensino básico, precisam de frequentar e concluir um ciclo de estudos conducente ao grau de mestre numa dessas especialidades ou numa combinação dessas especialidades (Decreto-Lei n. ${ }^{\circ}$ 79/2014).

O intervalo de idades dos participantes é dos 20 aos 38 anos, com predominância do intervalo 20-22 anos. A maioria dos participantes é do sexo feminino $(n=40)$ e apenas um do sexo masculino. Embora se trate de uma amostra por conveniência, as características em termos de idade são semelhantes às de outros cursos de formação inicial de professores em Portugal, que são maioritariamente frequentados por mulheres (DGEEC, 2019) ${ }^{1}$.

1 No ano letivo 2018/19 estavam inscritos no curso de licenciatura em Educação Básica, em instituições do ensino público e privado, 2773 mulheres e 170 homens. 
Todos os participantes deram o seu consentimento informado para a participação voluntária no estudo e concordaram com a utilização dos dados individuais recolhidos para efeitos de investigação em educação, com total respeito pelo seu anonimato. $\mathrm{O}$ seu anonimato foi assegurado através da codificação das respostas (E1 a E41).

\section{Métodos de recolha de dados}

Para a recolha de dados aplicou-se a professores em formação inicial um questionário adaptado a partir do aplicado no projeto BIOHEAD-CITIZEN (2008), ao qual se acrescentaram questões sobre a perspetiva da origem das espécies que defendem e sobre o seu posicionamento quanto ao ensino da evolução. O questionário é constituído por 18 perguntas (ver anexo). As cinco primeiras visavam recolher dados sociodemográficos e relativos ao percurso académico dos participantes. A sexta e a sétima questão destinavam-se a aferir o posicionamento dos participantes quanto às crenças religiosas. A maioria das questões seguintes ( 8 a 16) foi adaptada a partir das perguntas relacionadas com a evolução do inquérito BIOHEAD-CITIZEN (A33, A44, A62, A64, B7, B28, B29a, B29b, B42, B43, B44, B45, B46, B47, B48), conforme apresentadas no anexo do estudo realizado por Clément et al. (2008). Nas questões A33, A44 e B7 preferiu-se não se usar a escala de 1 a 4 quanto à concordância ou não concordância com as afirmações propostas, mas apenas as expressões "concordo" e "não concordo" de modo a obter como resultados posições claramente evolucionistas ou criacionistas. Considerou-se esta opção metodológica válida porque a análise dos resultados de outros estudos mostra que as escalas 1 e 2 tendem a ser agregadas num cluster evolucionista e as escalas 3 e 4 num cluster criacionista ou vice-versa (Araújo et al., 2009; Silva et al., 2014). A décima sétima questão era relativa ao posicionamento dos estudantes sobre o ensino da evolução, tal como apresentada por Campos (2013). A última questão era de resposta aberta e consistia numa reflexão, entre 150 a 200 palavras, com vista a aferir a perspetiva defendida pelos participantes quanto à origem das espécies.

O questionário foi aplicado, num primeiro momento, numa turma de formação de professores no ano letivo 2018/19. A partir dessa aplicação foram realizados pequenos ajustes que conduziram à versão final do questionário aplicado no ano letivo 2019/20. O questionário foi aplicado aos estudantes antes de receberem formação sobre evolução, mas após terem recebido formação sobre a origem da vida (hipótese autotrófica) no enquadramento da frequência de uma unidade curricular designada Ciências da Terra e da Vida.

\section{Metodologia de análise de dados}

Os resultados das questões 8 a 16 foram expressos em gráficos de barras. De seguida, foram analisados com o intuito de identificar a prevalência de perspetivas evolucionistas ou criacionistas dos participantes. Para melhor ilustrar e fundamentar a análise, apresentam-se excertos das respostas dos participantes à questão aberta. Os resultados das questões 8 a 16 foram cruzados com estudos análogos que tiveram por 
base o inquérito do projeto BIOHEAD-CITIZEN (Araújo et al., 2009; Clément et al., 2008; Silva et al., 2014).

Atendendo ao reduzido tamanho amostral, Fisher exact-tests foram usados para testar a associação entre pares de questões com respostas binomiais. Estes testes permitem substituir testes de chi-quadrado na análise de tabelas de contingência de 2x2 quando o tamanho amostral é reduzido (Sokal \& Rohlf, 1969). Para testar a correlação entre as categorias de respostas binomiais com as crenças religiosas dos inquiridos, foram utilizados testes de Freeman-Halton que são uma extensão aos Fisher exact-tests utilizados para tabelas de contingência maiores do que $2 \mathrm{x} 2$. Todos os testes estatísticos foram realizados com o software estatístico SPSS v23.

\section{Apresentação e discussão dos resultados}

\section{Percurso académico}

Mais de metade dos participantes (54\%; $\mathrm{n}=22$ ) mencionaram ter recebido formação no seu percurso escolar relacionada com a teoria da evolução, com a seguinte distribuição: $1 .^{\circ}$ ciclo $(n=3) ; 2 .^{\circ}$ ciclo $(n=6) ; 3 .^{\circ}$ ciclo $(n=11)$; Ensino secundário ou profissional $(n=13)$. Salienta-se que, quanto aos dados anteriores, alguns participantes referiram ter recebido essa formação em mais do que um nível de ensino. A predominância da formação sobre evolução no $3 .^{\circ}$ ciclo e ensino secundário está em conformidade com a sua presença explícita no currículo português nesses níveis de ensino. Por exemplo, no 3. ${ }^{\circ}$ ciclo, ao nível do 9. ${ }^{\circ}$ Ano, uma das aprendizagens essenciais relaciona-se com a explicação da relação entre os fatores hereditários, a informação genética e o modo como a reprodução sexuada condiciona a diversidade intraespecífica e a evolução das populações (ME, 2018). Ao nível do ensino secundário, é dedicada uma unidade de ensino à temática dos mecanismos de evolução no $11 .^{\circ}$ ano da disciplina de Biologia e Geologia (ME, 2003).

Quanto às disciplinas no âmbito das quais os participantes afirmam terem recebido formação sobre evolução $(n=22)$, incluem: Ciências Naturais $(n=14)$; Biologia $(n=12)$; Geologia $(n=3)$. Com uma referência, encontram-se as disciplinas de História e Geografia de Portugal, Estudo do Meio, História e Física e Química A. Portanto, os dados anteriores mostram que as disciplinas em que receberam mais formação sobre evolução foram as Ciências Naturais, a Biologia e a Geologia, o que está em conformidade com a presença direta ou indireta dessa temática no currículo português. No enquadramento da sua frequência no ensino superior e no curso de Educação Básica, apenas abordaram essa temática no $3 .^{\circ}$ ano $/ 2 .^{\circ}$ semestre, na unidade curricular de Ciências da Terra e da Vida.

\section{Crenças religiosas}

A Tabela 1 resume a posição dos participantes relativamente às crenças religiosas, através da análise dos resultados recolhidos nas suas respostas às questões 6 e 7. 
Tabela 1. Frequência da posição dos participantes relativamente às crenças religiosas

\begin{tabular}{|c|c|c|}
\hline Crença religiosa & $\begin{array}{c}\text { Frequência } \\
\text { absoluta }(n=41)\end{array}$ & $\begin{array}{l}\text { Frequência } \\
\text { relativa }\end{array}$ \\
\hline \multicolumn{3}{|l|}{ Teísta } \\
\hline $\begin{array}{l}\text { Acredita na existência de uma entidade divina que influencia } \\
\text { diretamente a vida dos seres humanos. }\end{array}$ & 11 & 27 \\
\hline \multicolumn{3}{|l|}{ Deísta } \\
\hline $\begin{array}{l}\text { Acredita na existência de uma entidade divina, mas apenas } \\
\text { observadora, isto é, que não interfere direta ou indiretamente na } \\
\text { vida dos seres humanos. }\end{array}$ & 19 & 46 \\
\hline \multicolumn{3}{|l|}{ Ateísta } \\
\hline \multicolumn{3}{|l|}{ Não acredita na existência de uma entidade divina. } \\
\hline Outros & 2 & 5 \\
\hline
\end{tabular}

Quanto aos participantes com crenças religiosas, a distribuição da religião que professam é essencialmente cristã/católica. Muitos participantes com crenças religiosas preferiram não identificar a sua religião.

\section{Posição sobre a evolução e criacionismo}

Uma das questões visava medir as convicções dos estudantes a favor ou contra a teoria da evolução (Questão B29a do inquérito BIOHEAD-SCITIZEN) e outra pergunta as suas convicções a favor o criacionismo (Questão B29b do inquérito BIOHEADSCITIZEN). O gráfico da Figura 1 ilustra as respostas afirmativas dos inquiridos às questões B29a e B29b, assim como os que responderam afirmativamente a ambas as explicações e os que responderam que nenhuma contradiz as suas crenças, cruzando-as com as suas crenças religiosas.

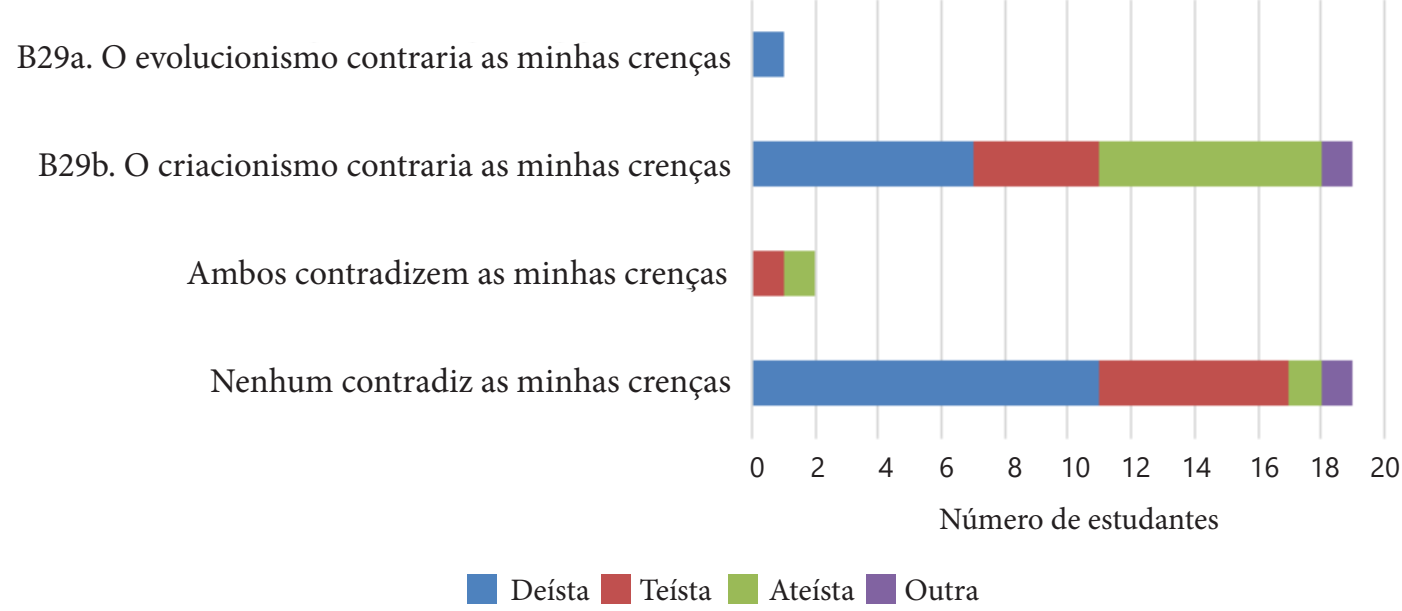

Figura 1. Gráfico das respostas positivas dos inquiridos às questões B29a e B29b, de acordo com as suas crenças religiosas (deísta, teísta, ateísta ou outra)

A distribuição dos resultados obtidos no presente estudo mostram: i) uma menor 
frequência de participantes para quem a teoria da evolução contradiz as suas crenças, em comparação com os resultados obtidos por Clément (2008) para os professores portugueses que não lecionam Biologia; ii) uma frequência relativa (46\%) semelhante aos obtidos para os professores da $1 .{ }^{\mathrm{a}}$ a $4 .{ }^{\mathrm{a}}$ séries do Ensino Fundamental e de estudantes do curso de Pedagogia, no estudo realizado por Araújo et al. (2009), na medida em que $47 \%$ dos respondentes nesse estudo convivem bem com as duas conceções.

Os resultados dos testes de Freeman-Halton suportam a não existência de uma associação entre as crenças religiosas dos inquiridos e as suas respostas à questão B29a $(\mathrm{p}=1,0)$. De facto, dos 38 estudantes que indicaram que a teoria da evolução não contradiz as suas crenças, 10 classificaram-se como teístas e 22 como deístas, o que sugere uma separação, e ao mesmo tempo convivência, entre as explicações religiosas e científicas para a origem da vida, no mesmo indivíduo. Esta convivência é ilustrada a seguir na afirmação de um estudante teísta (E32) e na afirmação de um estudante deísta (E22).

Uma vez que sou cristã, na minha opinião, foi Deus que deu origem a todas as espécies. Este primeiro criou os Céus e a Terra, de seguida a água, a luz, a terra, os animais e por último o homem. Deus criou a "base" da vida e depois estas espécies foram evoluindo ao longo dos tempos, de forma natural. (E32);

Creio que a origem das espécies engloba fatores naturais devido à influência do ambiente envolvente bem como fatores de seleção natural que vão ao encontro de perspetivas darwinistas e também alguma influência religiosa, visto que, segundo as minhas crenças, Deus criou o primeiro ser humano. (E22).

Os evolucionistas convictos do presente estudo responderam da seguinte forma na questão de reflexão sobre a origem das espécies: "Eu acredito que a explicação para a origem das espécies deve-se à evolução do mundo, onde os organismos vivos se adaptam gradualmente através da seleção natural." (E24); "A origem da vida pode ser explicada através de um processo natural e sem qualquer interferência por parte de uma entidade divina. O mesmo acontece com o desenvolvimento da humanidade." (E35). Alguns estudantes relataram, inclusivamente, uma certa confusão devido ao confronto entre a perspetiva religiosa e científica sobre a origem e evolução da vida:

A meu ver a origem das espécies é algo mais complexo do que aquilo que podemos imaginar. Muitas pessoas acreditam cegamente naquilo que lhes é dito, no entanto, por vezes questiono-me muito acerca de como surgimos se é como a ciência diz ou se é o que Deus diz... Acho que nunca iremos ter a certeza absoluta, pois para isso teríamos que presenciar pessoalmente o que aconteceu e como a vida surgiu na Terra. Muitas são as hipóteses, muitas são as teorias, mas qual será a verdade absoluta? A meu ver a ciência é algo mais exato e dever-nos-ia dar a resposta mais acertada, mas não sei se a parte da religião também é algo que explica bem a origem das espécies. Eu não defendo nada em concreto, mas a meu ver a vida surgiu a partir do Big Bang e de células que apareceram depois disso que formaram organismos e assim foram-se formando as mais variadas espécies que hoje em dia temos conhecimento. (E26)

Esta acomodação de diferentes perspetivas explicativas da vida também foi 
identificada em outros estudos (Silva et al., 2014; Silva et al., 2015). Uma explicação para a aceitação aparente e sem conflito entre as ideias criacionistas e evolucionistas foi apresentada por Caldeira, Araújo e Carvalho (2012). Estes investigadores sugerem que é possível a coexistência no mesmo individuo de dois ou mais significados para a mesma palavra ou conceitos, sendo cada um deles evocado no contexto apropriado. $\mathrm{Na}$ mesma linha de pensamento, a NASIM (2008) conclui que a aceitação das evidências da evolução pode ser compatível com a fé religiosa, tendo em conta que a ciência e a religião são formas de conhecimento distintas e que se dirigem a aspetos do saber humano de maneiras diferentes. Por essa razão, é possível que os professores e os futuros professores com crenças religiosas compreendam o significado de evolução, sem rejeitarem outras ideias para a origem e alteração da vida.

A questão oposta (B29b), relacionada com o facto de o criacionismo contradizer as crenças pessoais, enquanto ideia da criação por uma força sobrenatural, incluindo a noção de que essa força criou o ser humano, foi respondida afirmativamente por 51\% $(\mathrm{n}=21$; Figura 1$)$. Um estudante manifestou-se como um criacionista convicto:

Na minha opinião, e de acordo com as minhas crenças Deus criou o homem e os demais seres vivos já na forma atual há menos de 10 mil anos. Já sobre os fósseis, incluindo os dinossauros, são animais que não conseguiram embarcar na Arca de Noé a tempo de salvarem-se do dilúvio. Deus terá criado todos os seres vivos seguindo um propósito e uma intenção. (E12)

Os resultados dos testes de Freeman-Halton suportam a existência de uma associação entre as crenças religiosas dos inquiridos e as suas respostas à questão B29b $(\mathrm{P}=0,0498)$, devido à elevada frequência de ateístas a responderem que o criacionismo contraria as suas crenças. Clément et al. (2008) também determinaram que os professores ateístas ou agnósticos são claramente evolucionistas. De facto, os oito estudantes que se consideraram ateístas no presente estudo mantêm solidez nas suas conceções ao afirmarem na questão de reflexão sobre a origem das espécies que o criacionismo contradiz as suas crenças, como exemplifica o seguinte excerto:

A explicação para a origem das espécies que eu defendo é que a vida surgiu da evolução destas mesmas. Esta ideia enquadra-se na hipótese heterotrófica e autotrófica, em que se defende a criação da vida na Terra a partir de moléculas simples. Assim, a vida formouse a partir de moléculas simples, que evoluíram transformando-se e juntando-se dando origem a células mais complexas, formando assim corpos celulares. Sendo que há provas científicas de que a vida começou desta forma, como experiências e fósseis que podem ser estudados, é muito mais fácil acreditar nesta hipótese, pois temos materiais palpáveis e científicos da sua evolução. Um pouco mais difícil de aceitar é a vida ter começado dirigidos por Deus ou outra entidade religiosa ou superior, pois não há provas de que estas entidades realmente tiveram um papel ativo neste acontecimento, como não há provas não há como acreditar nessa hipótese. (E5)

A resposta do estudante E5 mostra que associa as explicações da ciência a um suporte por evidências, "provas" e as explicações da religião a ausência de "provas". 
Quanto aos estudantes teístas, apesar das suas crenças, cinco estudantes referiram que o criacionismo contradiz as suas crenças, o que parece revelar, mais uma vez, alguma conciliação entre crenças religiosas e o evolucionismo.

\section{Posição sobre o aparecimento da espécie humana}

De acordo com o Fisher Exact tests, existe uma associação significativa entre as respostas a estas duas questões $(\mathrm{p}=0,003)$. Os indivíduos que respondem não concordo na A44 (O aparecimento da espécie humana (Homo sapiens) foi o objetivo da evolução dos organismos?), tendem a concordar mais frequentemente com a A33 (O aparecimento da espécie humana (Homo sapiens) foi tão improvável como o aparecimento de qualquer outra espécie?), o que é conforme com o facto de as duas afirmações serem concetualmente opostas.

Relativamente à afirmação "O aparecimento da espécie humana (Homo sapiens) foi o objetivo da evolução dos organismos" (A44 do inquérito BIOHEAD-SCITIZEN), $59 \%$ dos participantes concordaram com a mesma $(n=24)$. Essa ideia de progressão biológica parece estar vincada no discurso de alguns estudantes, como mostram os seguintes excertos da questão de reflexão sobre a origem das espécies: “(...) as primeiras células através do ambiente envolvente foram sofrendo mutações e adaptações que, mais tarde, deram origem a uma espécie mais desenvolvida, o ser humano." (E2); “(...) Isto porque acredito que de um peixe, por exemplo, se originou um humano, devido às suas transformações biológicas ao longo de milhões de anos (...)" (E27);

Eu penso que a origem das espécies foi algo relacionado com a evolução das bactérias e dos vírus e que por isso é que existe uma evolução (...) com essa evolução pudemos então chegar a nossa espécie o ser humano que é a espécie mais evoluída até hoje. (E32)

Os resultados mostram que os estudantes colocaram maioritariamente o ser humano num plano diferente do processo evolutivo, considerando-o como o culminar do mesmo, resultado que está em conformidade com resultados de estudos anteriores com estudantes de um bacharelato em Ciências Biológicas (Silva et al., 2014).

Quanto à afirmação "O aparecimento da espécie humana (Homo sapiens) foi tão improvável como o aparecimento de outras espécies" (A33 do inquérito BIOHEADSCITIZEN), $61 \%$ dos participantes $(n=25)$ responderam que concordavam, enquanto os restantes manifestaram discordar da mesma. Na questão de reflexão sobre a origem das espécies, um estudante que se classificou como deísta parece conciliar ideias evolucionistas com o criacionismo do ser humano acerca da origem do ser humano:

No meu ponto de vista a origem das espécies envolve fatores naturais devido à influência do meio envolvente, por outro lado concordo também com a teoria de que Deus criou o primeiro ser humano, pois vai ao encontro das minhas crenças religiosas. (E23)

A aproximação às ideias evolucionistas dos participantes neste estudo foi superior à dos estudantes do bacharelato em Ciências Biológicas do estudo de Silva et al. (2014). De facto, a maioria dos estudantes de Ciências Biológicas (57\%) não concorda com a 
ideia de acaso para aparecimento do ser humano, o que contrasta com o valor de $39 \%$ obtido para os estudantes inquiridos no presente trabalho.

\section{Concordância com afirmações sobre a origem da vida}

O gráfico da Figura 2 apresenta os resultados da concordância dos participantes com uma de quatro afirmações sobre a origem da vida (A64 do inquérito BIOHEADSCITIZEN).

De certeza que Deus criou a vida.

A origem da vida pode ser explicada por um processo natural que é dirigido por Deus.

A origem da Vida pode ser explicada por um processo natural, sem considerar a hipótese de que Deus criou a vida.

De certeza que a origem da vida resultou de um processo natural.

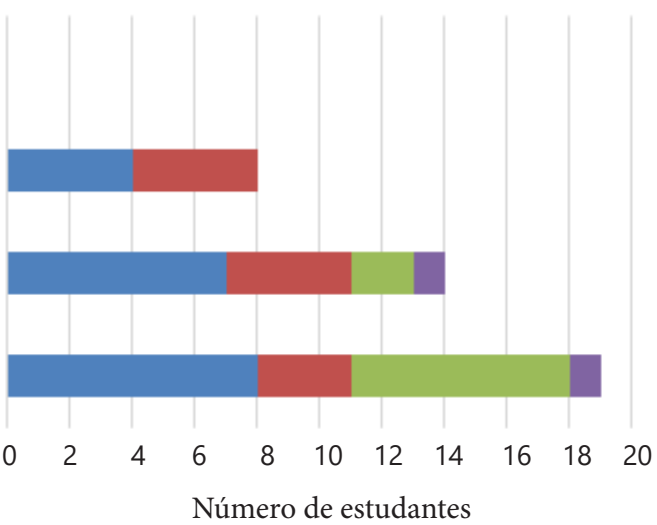

Deísta $\square$ Teísta Ateísta $\square$ Outra

Figura 2. Gráfico das respostas dos participantes quanto à concordância com uma de quatro afirmações sobre a origem da vida, de acordo com com as suas crenças religiosas

Enquanto as afirmações "De certeza que Deus criou a vida" e "A origem da vida pode ser explicada por um processo natural que é dirigido por Deus" são criacionistas, as afirmações "A origem da vida pode ser explicada por um processo natural, sem considerar a hipótese de que Deus criou a vida" e "De certeza que a origem da vida resultou de um processo natural" são evolucionistas. Os resultados permitem retirar as seguintes ilações: i) nenhum participante, inclusivamente os teístas, considera dogmaticamente que, "De certeza Deus criou a vida”; ii) a afirmação "A origem da vida poder ser explicada por um processo natural dirigido por Deus", é suportada por alunos de todas as crenças, menos os ateístas. O seguinte excerto ilustra essa conceção: "Para mim, as espécies, nomeadamente a espécie humana surgiu através da evolução de organismos, na qual acredito que de alguma forma Deus teve "mão" nessa evolução." (E39); iii) alguns participantes teístas consideram dogmaticamente que “(...) a origem da vida resultou de um processo natural", o que evidencia a conciliação entre a ciência e as suas crenças religiosas. De facto, os resultados evidenciam que a maioria dos inquiridos $(46 \% ; n=19)$ concorda que a origem da vida resultou indubitavelmente de um processo natural, como ilustrado nos seguintes excertos das suas reflexões sobre a origem das espécies: "Eu acredito que o universo surgiu através do Big Bang e que a vida começou por ser apenas pequenas células, que foram evoluindo até criarem as diferentes espécies. Considero que o ser humano resulta da evolução dessas mesmas células." (E14); “A origem das espécies para mim aconteceu de um processo natural, através de estudos de cientistas. Apesar 
da existência de várias teorias, de certeza que algumas fazem mais sentido. Para mim, só a ciência consegue explicar e não há uma só teoria confirmada de como surgiu as espécies" (E18). A Tabela 2 compara estes resultados com outros estudos.

Tabela 2. Comparação entre diferentes estudos da concordância dos participantes com uma de quatro afirmações sobre a origem da vida

\begin{tabular}{|c|c|c|c|c|c|c|}
\hline Participantes & $\begin{array}{l}\text { 1. Processos } \\
\text { evolucionistas }\end{array}$ & $\begin{array}{l}\text { 2. Processos } \\
\text { evolucionistas } \\
\text { sem Deus }\end{array}$ & $\begin{array}{l}\text { Evolucionismo } \\
(\text { Total }=1+2)\end{array}$ & $\begin{array}{l}\text { 3. Processos } \\
\text { evolucionistas } \\
\text { com Deus } \\
\text { (Design } \\
\text { inteligente) }\end{array}$ & $\begin{array}{c}4 . \\
\text { Deus }\end{array}$ & $\begin{array}{c}\text { Criacionismo } \\
(\text { Total }=3+4)\end{array}$ \\
\hline $\begin{array}{l}\text { Estudantes } \\
\text { de Educação } \\
\text { Básica }\end{array}$ & $46 \%$ & $34 \%$ & $80 \%$ & $20 \%$ & $0 \%$ & $20 \%$ \\
\hline $\begin{array}{l}\text { Estudantes } \\
\text { de Pedagogia } \\
\text { (Araújo et al., } \\
\text { 2009) }\end{array}$ & $10 \%$ & $10 \%$ & $20 \%$ & $28 \%$ & $52 \%$ & $80 \%$ \\
\hline $\begin{array}{l}\text { Professores } \\
\text { de Biologia } \\
\text { (Clément et al., } \\
\text { 2008) }\end{array}$ & $46 \%$ & $25 \%$ & $71 \%$ & $26 \%$ & $3 \%$ & $29 \%$ \\
\hline $\begin{array}{l}\text { Outros } \\
\text { professores } \\
\text { (Clément et al., } \\
\text { 2008) }\end{array}$ & $32 \%$ & $15 \%$ & $47 \%$ & $45 \%$ & $8 \%$ & $53 \%$ \\
\hline $\begin{array}{l}\text { Estudantes em } \\
\text { formação inicial } \\
\text { de professores } \\
\text { em Ciências } \\
\text { Biológicas } \\
\text { (Silva et al., } \\
\text { 2014) }\end{array}$ & $21 \%$ & $7 \%$ & $28 \%$ & $52 \%$ & $20 \%$ & $72 \%$ \\
\hline 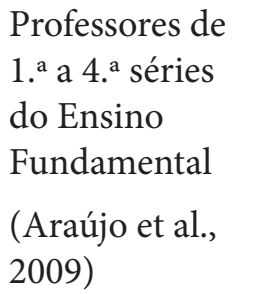 & $10 \%$ & $2 \%$ & $12 \%$ & $28 \%$ & $60 \%$ & $88 \%$ \\
\hline
\end{tabular}

Comparando os resultados dos estudantes em formação inicial de professores inquiridos durante este estudo (estudantes de Educação Básica) com os de outros estudantes em formação de professores, neste caso de Pedagogia (Araújo et al., 2009), constata-se que, no primeiro grupo, dominam as conceções evolucionistas, enquanto no segundo predominam as conceções criacionistas. Os dados da tabela anterior mostram 
ainda que os resultados mais próximos dos estudantes inquiridos neste estudo são os obtidos com os professores de Biologia (Clément et al., 2008). Note-se que os professores de Biologia desse trabalho, maioritariamente europeus, são os que apresentam mais conceções evolucionistas, o que contrasta com os professores brasileiros em formação de Biologia, que são aqueles que apresentam menos conceções evolucionistas, como mostra o trabalho de Silva et al. (2014).

\section{Concordância com afirmações sobre a origem do ser humano}

A questão seguinte era relativa ao posicionamento dos participantes quanto ao aparecimento específico da espécie humana (B28 do inquérito BIOHEAD-SCITIZEN) (Figura 3).

De certeza que Deus criou o ser humano.

A origem da humanidade pode ser explicada por processos associados à evolução que são dirigidos por Deus

A origem da humanidade pode ser explicada por processos associados à evolução sem considerar a hipótese de que Deus criou o ser humano

De certeza que a origem do ser humano resultou de processos associados à evolução

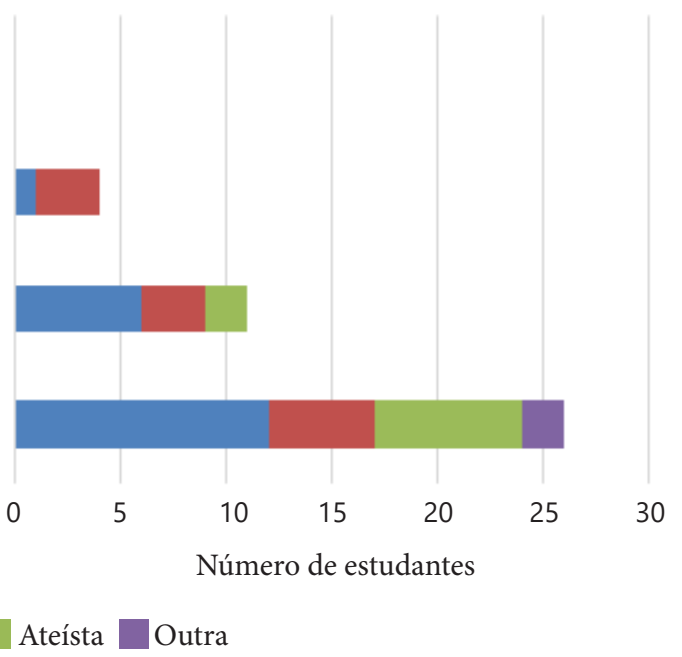

Figura 3. Gráfico das respostas dos participantes quanto à concordância com uma de quatro afirmações sobre a origem do ser humano, com o cruzamento com as suas crenças religiosas

Os dados evidenciam que a maioria dos inquiridos $(63 \% ; n=26)$ concorda que a origem do ser humano resultou de processos evolutivos. Note-se que houve mais estudantes a considerarem a existência de uma origem exclusivamente natural para o ser humano, em comparação com a questão anterior, mais generalista, sobre a origem da vida. Estes valores são superiores aos obtidos para os professores da $1 .{ }^{\mathrm{a}}$ a $4 .^{\mathrm{a}}$ séries do Ensino Fundamental e de estudantes do curso de Pedagogia, no estudo realizado por Araújo et al. (2009). Onze inquiridos (27\%) concordam que a origem da humanidade pode ser explicada por processo evolutivos totalmente naturais, sem considerar a hipótese de Deus ter criado o ser humano. Esta foi a resposta menos selecionada pelos participantes no estudo realizado por Araújo et al. (2009). Quatro estudantes (10\%) defendem que a origem da humanidade pode ser explicada por processos evolucionistas dirigidos por Deus. A reflexão destes estudantes sobre a origem das espécies mostra que foi difícil conciliar uma origem da vida explicada por processos naturais com o aparecimento do ser humano: 
$\mathrm{Na}$ minha opinião a origem das espécies é derivada da evolução dos organismos ao longo do tempo e a sua devida adaptação ao ambiente envolvente. Concordo com a teoria do Big Bang mas lá no fundo também acredito que exista alguma razão para as coisas acontecerem de certa forma. Existe aquela necessidade de acreditar em algo sobrenatural para aceitar certos acontecimentos na nossa vida em vez de evidências da ciência, mesmo que se façam muitos estudos, ninguém sabe a $100 \%$ como é que as coisas se passaram, apenas têm uma opinião formulada que se sustenta nessas mesmas pesquisas que realizam, mas o certo é que não estavam propriamente lá para ver com os próprios olhos como foi a origem do universo e esta será sempre a questão que está no intimo de cada ser humano, de onde é que aparecemos ao certo, qual é o sentido da vida e, o mais importante, qual é o nosso papel nesta passagem pela Terra. (E22)

Nenhum estudante nesta questão referiu ter a certeza de que Deus criou o ser humano, no entanto, na reflexão, alguns parecem acreditar exatamente nesse processo, como mostra o seguinte excerto: “(...) Na minha opinião, deus criou o universo e os seres vivos. Segundo isto, o homem foi feito à imagem e semelhança de Deus, logo não descende dos primatas (...)" (E38).

Globalmente, 90\% dos estudantes apresentam um pensamento evolucionista e $10 \%$ um pensamento criacionista quanto à origem do ser humano. Estes valores contrastam com os do estudo de Araújo et al. (2009), na medida em que 79,06\% dos professores da $1 .{ }^{\mathrm{a}}$ a $4 .^{\mathrm{a}}$ séries e $77,66 \%$ dos estudantes do curso de pedagogia apresentam conceções criacionistas.

\section{Avaliação da importância de fatores sobre a evolução das espécies}

As perguntas B42 a B48 do inquérito BIOHEAD-SCITIZEN visavam que cada respondente avaliasse a importância de seis fatores na evolução das espécies: i) acaso; ii) seleção natural; iii) os organismos, ou pelo menos alguns dos seus componentes, foram concebidos por uma inteligência superior (design inteligente); iv) o ambiente envolvente; v) transposões (genes capazes de alterar a sua posição no genoma hospedeiro); vi) vírus (estruturas formadas principalmente por uma cápside proteica que envolve o material genético); vii) Deus. Os resultados estão expressos nos gráficos da Figura 4.

Os resultados sobre o principal fator ao qual os inquiridos atribuíram "muita importância" foi ao ambiente envolvente (71\%; $n=29)$. Acerca do ambiente, alguns estudantes manifestaram ideias darwinistas sobre a sua influência na origem das espécies: “(..) Ou seja, as espécies adaptadas às condições do ambiente, serão capazes de sobreviver, de se reproduzir e de gerar descendentes.” (E9). 


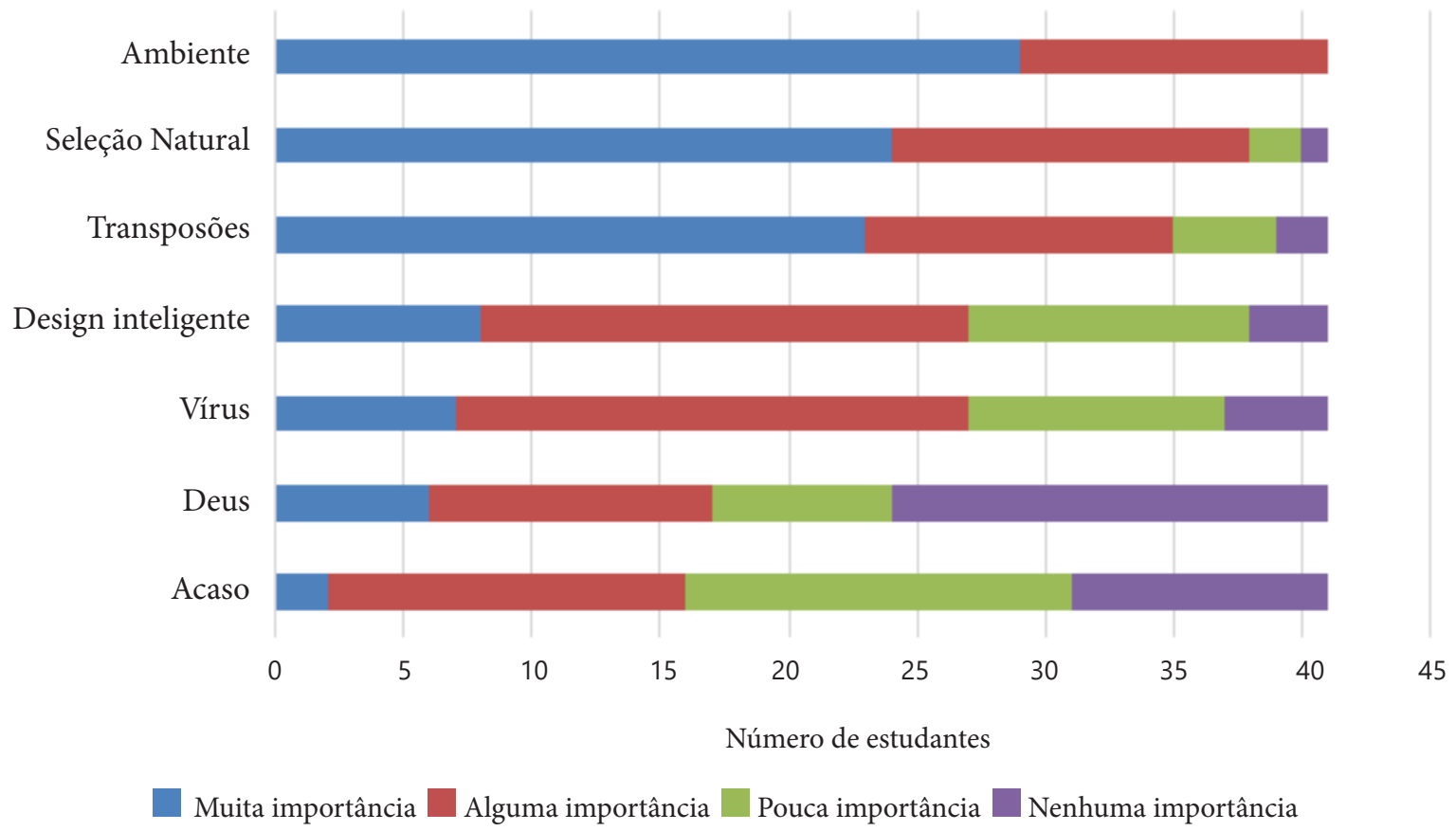

Figura 4. Gráfico da avaliação da importância de sete fatores na evolução das espécies

Contudo, outros manifestam conceções claramente lamarckistas e/ou teleológicas sobre a influência do ambiente:

$\mathrm{Na}$ minha opinião, a origem das espécies deu-se através de várias modificações no organismo das espécies primárias, conforme as necessidades das mesmas e as alterações ambientais que foram ocorrendo ao longo tempo (...). (E41).

(...) Por último considero que a natureza também teve o seu contributo na evolução das espécies, por exemplo, as espécies tiveram que se adaptar as condições ambientais ou ter certas características para poderem sobreviver, reproduzir-se e gerar novos seres, as zebras se não tivessem o seu pescoço tão longo não chegariam às folhas das árvores para se alimentarem. (E25)

Estas explicações teleológicas para o funcionamento da evolução também foram identificadas em outros estudos (Sickel \& Friedrichsen, 2013; Stover \& Mabry, 2007; Zuzovsky, 1994).

O segundo fator mais elencado como tendo influência na evolução das espécies foi a seleção natural (59\%; $n=24)$. Alguns estudantes manifestaram ideias corretas sobre o funcionamento desse processo: “(...) acho que a origem da vida se deve a uma seleção natural, onde os seres vivos mais aptos, por apresentarem a caraterística mais vantajosa, se reproduziram mais, transmitindo essa caraterística à descendência ao longo das gerações. Os seres vivos menos aptos, por não apresentarem caraterísticas vantajosas, eram eliminados.” (E4).; “(...) Foi Charles Darwin que propôs a teoria da evolução biológica por seleção natural (...)” (E8). 
O valor mais elevado de "alguma importância" foi atribuído aos vírus (49\%; $\mathrm{n}=20$ ), agentes mutagénicos, o que também está em consonância com os processos evolucionistas. Ao design inteligente foi atribuído o segundo valor de "alguma importância" $846 \% ; n=19$ ) o que reflete ideias criacionistas. Note-se que ao acaso foi atribuído o segundo valor de "nenhuma importância", sendo "Deus" o fator ao qual o maior número de inquiridos atribuiu nenhuma importância. Isto evidencia que alguns estudantes não compreendem que o acaso também está envolvido na evolução, como no caso da deriva genética.

\section{Conceções sobre o ensino da evolução}

Acerca das conceções sobre o ensino da evolução, a maioria dos inquiridos neste estudo (88\%; $\mathrm{n}=36)$ manifestou que os professores devem tanto lecionar a evolução como o criacionismo de modo aos alunos decidirem qual a explicação que consideram mais adequada para a origem das espécies. Note-se que os resultados do presente estudo estão em consonância com os obtidos por Sickel e Friedrichsen (2013), em cujo trabalho os professores referiram que o criacionismo deve ser ensinado a par da evolução. Esse caráter conciliador está patente na reflexão do seguinte estudante: "Penso que na escola deveríamos aprender as duas vertentes, tanto a da religião como a da ciência, de modo a que conseguíssemos entender melhor as diferenças que existem entre cada uma, chegando assim, às nossas próprias conclusões." (E11). Porém, de acordo com Campos (2013) essa conceção é considerada errada porque "a religião e a ciência são actividades muito diferentes e os pontos de vista religiosos não pertencem a uma aula de ciência" (p. 141). A NASIM (2008) também alertou que a pressão para diminuir a presença da evolução ou aumentar a presença de alternativas não científicas nas escolas públicas pode comprometer a educação em ciências. Ensinar ideias criacionistas nas aulas de ciências pode confundir os alunos sobre o que constituiu e o que não constitui ciência (NASIM, 2008). Contudo, no caso da presente amostra, a maioria dos estudantes (80\%; $\mathrm{n}=33$ ) não atribuiu à teoria da evolução um carácter religioso e consideraram que o ensino da evolução não viola a liberdade de expressão.

\section{Conclusões e Implicações}

Os estudantes em formação inicial de professores que participaram neste estudo possuem, maioritariamente, conceções evolucionistas sobre a origem das espécies, da vida e do ser humano. As conceções evolucionistas desta amostra de estudantes portugueses é superior, por exemplo, à dos estudantes brasileiros de Pedagogia uma vez que Araújo et al. (2009) determinaram que apenas 10\% são evolucionistas convictos. Os resultados confirmam estudos como o de Clément et al. (2008), no qual identificaram que as conceções evolucionistas mais moderadas estão presentes em países como Portugal, Finlândia, Itália e Hungria, enquanto as mais extremas manifestam-se na França e Estónia. 
De facto, os dados globais obtidos no presente estudo afastam-se de conceções criacionistas moderadas ou extremas. Porém, este trabalho também mostra que as conceções evolucionistas podem coabitar com uma diversidade de crenças religiosas. Alguns estudantes parecem acreditar numa origem divina da vida que, mais tarde, foi continuada por um processo evolucionista natural ou, pelo menos, dirigido por uma entidade divina, que desenvolveu e aperfeiçoou as espécies criadas inicialmente. A esse respeito, estudos como o de Araújo et al. (2009) sugerem que as crenças religiosas dos estudantes podem influenciar o desenvolvimento do tema da evolução em sala de aula. No presente estudo, os resultados evidenciaram que os estudantes em formação inicial de professores consideraram que a evolução deve ser ensinada a par do criacionismo, para que os alunos possam decidir sobre a posição que advogam. Por essa razão, e embora a evolução tenha uma expressão residual no currículo português nos primeiros níveis de ensino, concordamos com a sugestão de Silva et al. (2014) relativamente à necessidade de estudos que analisem o modo como os professores expressam nas aulas a sua acomodação, ou conflito, entre as explicações religiosas e científicas sobre a origem e a evolução da vida.

As respostas dos estudantes relativas à importância de determinados fatores sobre a evolução e na questão aberta de reflexão sobre a origem das espécies mostram que subsistem várias conceções inadequadas, como a convicção de que há uma progressão biológica até ao ser humano. Nesse sentido, é necessário avaliar os estudantes em formação inicial de professores também com outros instrumentos, como por exemplo o ACORNS (Nehm et al., 2012), para aferir o seu pensamento quanto a processos fundamentais da evolução, como a seleção natural. As conceções inadequadas sobre evolução apresentadas pelos estudantes reforçam a ideia referida em outros estudos de a formação em biologia ser uma variável muito importante para consolidar e aprofundar o conhecimento dos professores (Nehm \& Schonfeld, 2007; Sickel \& Friedrichsen, 2013) ou de estudantes do ensino superior (Stover \& Mabry, 2007) sobre a evolução. Por essa razão, uma das implicações deste estudo é a necessidade de reforçar a formação científica dos futuros professores do ensino básico em Portugal na componente de biologia, na qual a evolução deve ser um tema abordado em profundidade. Essa formação sobre evolução, a par do desenvolvimento do seu conhecimento pedagógico sobre o ensino da evolução, poderá capacitá-los para abordar essa temática com sucesso com os seus alunos.

\section{Agradecimentos}

Este trabalho foi financiado pela Fundação para a Ciência e Tecnologia, I. P., no âmbito de um contrato enquadrado nos números 4, 5 e 6 do Artigo 23. ${ }^{\circ}$, do Decreto-Lei 57/2016, de 29 agosto, alterado pela Lei 57/2017, de 19 julho, e do projeto UID/CED/00194/2019. Agradecemos aos estudantes que concordaram participar voluntariamente neste estudo. 


\section{Referências}

Abrie, A. L. (2010). Student teachers' attitudes toward and willingness to teach evolution in a changing South African environment. Journal of Biological Education, 44(3), 102107. https://doi.org/10.1080/00219266.2010.9656205

Alters, B. J., \& Nelson, C. E. (2002). Perspective: Teaching evolution in higher education. Evolution. International Journal of Organic Evolution, 56(10), 1891-1901. https://doi. org/10.1111/j.0014-3820.2002.tb00115.x

Araújo, E. S. N. N., Caldeira, A. M. A., Caluzi, J. J., \& Carvalho, G.S. (2009). Concepções criacionistas e evolucionistas de professores em formação e em exercício. In Actas do VII ENPEC - Encontro Nacional de Pesquisa em Educação em Ciências - Ciência, Cultura e Cidadania, Florianópolis, Brasil.

BIOHEAD-CITIZEN (2008). Final Report Summary - BIOHEAD-CITIZEN (Biology, health and environmental education for better citizenship). https://cordis.europa.eu/ project/rcn/79244/reporting/en

Caldeira, A. M. A., Araújo, E. S. N. N., \& Carvalho, G. S. (2012). Creationism and evolution views of Brazilian teachers and teachers-to-be. Journal of Life Sciences, 6(1), 99-109.

Campos, R. (Ed.) et al. (2013). Tenho uma pergunta ... e talvez tenha uma resposta. Um livro sobre evolução. CIBIO/Centro de Investigação em Biodiversidade e Recursos Genéticos.

Clément, P., Quessada, M. P., Laurent, C., \& Carvalho, G.S. (2008). Science and Religion: Evolutionism and Creationism in Education. A survey of teachers conceptions in 14 countries. In Proceedings of $t$ XIII IOSTE Symposium - The use of Science and Technology Education for Peace and Soustainable Development (pp. 1148-1155). Ankara: Palme Publications \& Bookshops.

Decreto-Lei n. ${ }^{\circ} 79 / 2014$ de 14 de maio. Diário da República, $1 .^{a}$ série, n. ${ }^{\circ} 92$, de 14 de maio de 2014, pp. 2819-2828. (Aprova o regime jurídico da habilitação profissional para a docência na educação pré-escolar e nos ensinos básico e secundário em Portugal.)

Direção-Geral de Estatísticas da Educação e Ciência (DGEEC) (2019). Inquérito Registo de Alunos Inscritos e Diplomados do Ensino Superior relativo a inscritos no ano letivo 2018/2019. https://www.dgeec.mec.pt/np4/1057.html

Harlen, W. (2015). Working with big ideas of science education. Science Education Programme of IAP.

Kose, E. O. (2010). Biology students' and teachers' religious beliefs and attitudes towards theory of evolution. H. U. Journal of Education, 38, 189-200. 
Levesque, P. J., \& Guillaume, A.M. (2010). Teachers, evolution, and religion: no resolution in sight. Review of Religious Research, 51(4), 349-365.

National Academy of Sciences and Institute of Medicine (NASIM) (2008). Science, Evolution, and Creationism. The National Academies Press.

Nehm, R. H., \& Schonfeld, I. S. (2007). Does increasing biology teacher knowledge of evolution and the nature of science lead to greater preference for the teaching of evolution in schools? Journal of Science Teacher Education, 18, 699-723. https://doi.org/10.1007/ s10972-007-9062-7

Nehm, R. H., Beggrow, E. P., Opfer, J. E., \& Ha, M. (2012). Reasoning About Natural Selection: Diagnosing Contextual Competency Using the ACORNS Instrument. The American Biology Teacher, 74(2), 92-98. https://doi.org/10.1525/abt.2012.74.2.6

Ministério da Educação (2003). Programa de Biologia e Geologia. 11. ${ }^{o}$ ano. Curso Científico-Humanístico de Ciências e Tecnologias. Ministério da Educação (Portugal).

Ministério da Educação (2018). Aprendizagens essenciais. Articulação com o perfil dos alunos. 9. ${ }^{\circ}$ ano. 3. ${ }^{\circ}$ Ciclo do Ensino Básico. Ciências Naturais. Ministério da Educação (Portugal).

Nehm, R. H., Kim, S. Y., \& Sheppard, K. (2009). Academic preparation in biology and advocacy for teaching evolution: Biology versus non-biology teachers. Science Education, 93(6), 1122-1146. https://doi.org/10.1186/1936-6434-6-23

Ross, A. (2007). Multiple identities and education for active citizenship. British Journal of Educational Studies, 55(3), 286-303. https://doi.org/10.1111/j.1467-8527.2007.00380.x

Sickel, A. J., \& Friedrichsen, P. (2013). Examining the evolution education literature with a focus on teachers: Major findings, goals for teacher preparation, and directions for future research. Evolution: Education and Outreach, 6(23), 1-15.

Sokal, R., Rohlf, F. J. (1969). Biometry. The principle and practice of statistics in biological research. Freeman, San Francisco.

Silva, H. M, Araújo, E. S. N. N., Gibram, D. E., \& Carvalho, G. S. (2014). Conceptual change about evolution and origins of life throughout an undergraduate course of Biological Sciences. In Proceedings of INTCESS 14 - International Conference on Education and Social Science Proceedings (p. 1249-1258), Istambul, Turkey.

Silva, H. M., Gibram, D. E., Tracana, R. B., \& Carvalho, G. S. (2015). Can one accept the Theory of Evolution and believe in God as well? Procedia - Social and Behavioral Sciences, 197, 770-779.

Stover, S., \& Mabry, M. (2007). Influences of Teleological and Lamarckian Thinking on Student Understanding of Natural Selection. Bioscene: Journal of College Biology Teaching, 33(1), 11-18. 
Vilelas, J. (2017). Investigação. O processo de construção do conhecimento (2. ${ }^{a}$ ed.). Edições Sílabo.

Ziadie. M. A., \& Andrews, T. C. (2018). Moving evolution education forward: A systematic analysis of literature to identify gaps in collective knowledge for teaching. CBE-Life Sciences Education, 17:ar11, 1-10. https://doi.org/10.1187/cbe.17-08-0190

Zuzovsky, R. (1994). Conceptualizing a teaching experience on the development of the idea of evolution: An epistemological approach to the education of science teachers. Journal of Research in Science Teaching, 31(5), 557-574. 


\section{Anexo}

Questionário sobre as conceções da origem da vida e das espécies aplicado a estudantes em formação inicial de professores (adaptado das questões sobre evolução do projeto BIOHEAD-CITIZEN)

Dados sociodemográficos e percurso académico

Questão 1. Indique a sua idade.

Questão 2. Indique o seu sexo.

$\square$ Feminino

Masculino

Questão 3. No seu percurso escolar recebeu formação sobre evolução antes de ingressar no ensino superior?

$\square \operatorname{Sim}$

$\square$ Não

Questão 4. Indique o(s) nível(s) de estudos em que recebeu formação sobre a teoria da evolução.

$\square 1 .^{\circ} \mathrm{CEB}$

$\square 2 .^{\circ} \mathrm{CEB}$

$\square 3 .^{\circ} \mathrm{CEB}$

$\square$ Ensino secundário

$\square$ Ensino profissional

$\square$ Não recebi

Questão 5. Selecione as disciplinas em que obteve a formação indicada na resposta 5.1.

Biologia

Geologia

Ciências Naturais

Outra

Posição sobre as crenças religiosas

Questão 6. Indique a sua posição relativamente às crenças religiosas.

$\square$ Teísta (Acredita na existência de uma entidade divina que influencia diretamente a vida dos seres humanos).

$\square$ Deísta (Acredita na existência de uma entidade divina, mas apenas observadora, isto é, que não interfere direta ou indiretamente na vida dos seres humanos).

$\square$ Ateísta (Não acredita na existência de uma entidade divina).

$\square$ Outra 
Questão 7. Se aplicável, indique a religião que professa. Se preferir não responder escreva apenas "Não respondo".

\section{Posição sobre a origem da vida e das espécies}

Questão 8. Selecione, da lista seguinte, as DUAS expressões que pensa estarem melhor associadas à origem da humanidade (adaptada da questão A62 do BIOHEAD-CITIZEN).

$\square$ Adão e Eva
$\square$ Australopithecus
$\square$ Criação
$\square$ Deus
$\square$ Seleção natural
$\square$ Evolução
$\square$ Outra

Questão 9. O aparecimento da espécie humana (Homo sapiens) foi o objetivo da evolução dos organismos? (adaptada da questão A44 do BIOHEAD-CITIZEN).

$\square$ Concordo

$\square$ Não concordo

Questão 10. O aparecimento da espécie humana (Homo sapiens) foi tão improvável como o aparecimento de qualquer outra espécie? (adaptada da questão A33 do BIOHEADCITIZEN).

$\square$ Concordo

$\square$ Não concordo

Questão 11. Com qual das afirmações seguintes concorda mais? (adaptada da questão A64 do BIOHEAD-CITIZEN).

$\square$ De certeza que a origem da vida resultou de um processo natural.

$\square$ A origem da vida pode ser explicada por um processo natural, sem considerar a hipótese de que Deus criou a vida.

$\square$ A origem da vida pode ser explicada por um processo natural que é dirigido por $\square$ Deus.

$\square$ De certeza que Deus criou a vida.

Questão 12. Com qual das afirmações seguintes concorda mais? (adaptada da questão B28 do BIOHEAD-CITIZEN).

$\square$ De certeza que a origem do ser humano resultou de processos associados à evolução.

$\square$ A origem da humanidade pode ser explicada por processos associados à evolução sem considerar a hipótese de que Deus criou o ser humano.

$\square$ A origem da humanidade pode ser explicada por processos associados à evolução que são dirigidos por Deus.

$\square$ De certeza que Deus criou o ser humano. 
Questão 13. O chimpanzé deve ser classificado no género "Homo" por 98,5\% do seu DNA ser igual ao do Homo sapiens (adaptada da questão B7 do BIOHEAD-CITIZEN).

$\square$ Concordo.

$\square$ Não concordo

Questão 14. A teoria da evolução contradiz as minhas crenças (adaptada da questão B29a do BIOHEAD-CITIZEN).

$\square \operatorname{Sim}$

$\square$ Não

Questão 15. O criacionismo (ideia da criação por uma força sobrenatural, incluindo a noção de que essa força criou o ser humano) contradiz as minhas crenças (adaptada da questão B29b do BIOHEAD-CITIZEN).

$\square \operatorname{Sim}$

$\square$ Não

Questão 16. Indique a sua avaliação da importância dos seguintes fatores na evolução das espécies (adaptada das questões B42 a B48 do BIOHEAD-CITIZEN).

\begin{tabular}{|l|l|l|l|l|}
\hline & $\begin{array}{l}\text { Muita } \\
\text { importância }\end{array}$ & $\begin{array}{l}\text { Alguma } \\
\text { importância }\end{array}$ & $\begin{array}{l}\text { Pouca } \\
\text { importância }\end{array}$ & $\begin{array}{l}\text { Nenhuma } \\
\text { importância }\end{array}$ \\
\hline Acaso & & & & \\
\hline $\begin{array}{l}\text { Seleção natural } \\
\text { Design inteligente (Certas } \\
\text { características do universo e dos seres } \\
\text { vivos são explicadas por uma causa } \\
\text { inteligente) }\end{array}$ & & & & \\
\hline O ambiente envolvente & & & & \\
\hline $\begin{array}{l}\text { Transposões (Genes que são capazes } \\
\text { de sair das suas posiçôes nos } \\
\text { cromossomas e mudar para outro } \\
\text { lugar na cadeia de ADN) }\end{array}$ & & & & \\
\hline Vírus & & & & \\
\hline Deus & & & & \\
\hline
\end{tabular}

Questão 17. Classifique como verdadeira ou falsa cada uma das afirmações seguintes sobre o ensino da evolução.

Os professores devem ensinar "os dois lados" do tema da evolução e deixar os estudantes decidir ou dar tempo igual para o evolucionismo e o criacionismo. (V/F)

A própria teoria da evolução é religiosa e, portanto, exigir que os professores ensinem evolução dá prioridade a uma religião em detrimento das restantes e viola a liberdade de expressão. (V/F)

Questão 18. Elabore uma reflexão sobre a explicação para a origem das espécies que defende (entre 150 a 200 palavras). 


\section{Bento Cavadas}

https://orcid.org/0000-0001-6021-6581

Instituto Politécnico de Santarém

Escola Superior de Educação de Santarém Departamento de Ciências Matemáticas e Naturais

Santarém, Portugal CeiED _ Universidade Lusófona Lisboa, Portugal bento.cavadas@ese.ipsantarem.pt

Xana Sá-Pinto

${ }^{\circ}$ https://orcid.org/0000-0002-6049-110X Universidade de Aveiro

Centro de Investigação em Didática e Tecnologia na Formação de Professores Departamento de Educação e Psicologia Aveiro, Portugal xanasapinto@gmail.com

Submetido em 16 de junho de 2020 Aceito em 31 de agosto de 2020 Publicado em 11 de janeiro de 2021 